\title{
A NEW APPROACH TO REMEDIATION OF SOILS CONTAMINATED BY PERSISTENT ORGANIC POLLUTANTS
}

\author{
Corcimaru S. ${ }^{l}$, Tanase Ana ${ }^{l}$, Cozma $V .{ }^{1}$, Rastimeșina Inna ${ }^{1}$, Postolachi Olga ${ }^{l}$, Sîrbu Tamara ${ }^{1}$, Slănina \\ Valerinal, Batîr Ludmila', Chiseliță O. ${ }^{l}$, Guțul Tatiana ${ }^{2}$ \\ ${ }^{I}$ The Institute of Microbiology and Biotechnology, Chisinau, Republic of Moldova \\ ${ }^{2}$ The Institute of Electronic Engineering and Nanotechnologies 'D.Ghitu', Chisinau, Republic of Moldova \\ e-mail: sergheicorcimaru@hotmail.com
}

Nano- and bioremediation technologies are widely studied and used among the most advanced means of environmental remediation, including in cases of soil contamination by persistent organic pollutants (POPs). However, the limitations known for each technology still prevent their full scale implementation. Relatively high economical costs and potential ecotoxicity of nanoparticles on the one hand, and relatively slow rates of bioremediation (especially in cases of heavy pollution) on the other, are just a few examples among the deficiencies that could be mentioned. The combined use of nanoparticles and bioremediation is currently suggested as a viable practical way to increase the efficiency of soil remediation via reducing its economical costs, increasing the sustainability, and shortening the time needed for decontamination. This new approach is known as Nanobioremediation, and the purpose of this work was to evaluate its potential for the Moldavian soils contaminated with trifluralin.

The polluted soil was sampled from a former pesticide deposit site near the town of Singera, and contained $30 \mathrm{mg} / \mathrm{kg}$ of trifluralin (and $2 \mathrm{mg} / \mathrm{kg}$ of DDTs). The nanomaterials used in the study were nanoscale zero-valent iron $(1.5-4 \mathrm{~nm})$ and nanomagnetite $(17-25 \mathrm{~nm})$. Nanoscale zero-valent iron was prepared from iron (III) chloride by the chemical reduction method in the presence of poly$\mathrm{N}$-vinylpyrrolidone as a stabilizer. Nanomagnetite was prepared according to the chemical coprecipitation method using iron (II) sulfate and iron (III) chloride in the presence of poly-Nvinylpyrrolidone as a stabilizer. The resulting nanomaterials were characterized by X-ray powder diffraction analysis, X-ray fluorescence analysis, scanning electron microscopyand FT-IRspectroscopy.

The combination of nano- and bioremediation techniques permitted to significantly increase the effectiveness of soil decontamination comparing to the controls with nanoremediation only and bioremediation only. The concentration of trifluralin left in the soil of the best variant of nanobioremediation was by many times smaller than in the best variants of nanoremediation and bioremediation. Moreover, comparing to the best case of bioremediation, nanobioremediation permitted to radically decrease the number of remediation manipulations and to considerably shorten the time needed for decontamination.

It was found that the studied nanoparticles were able (a) to decrease the toxicity of trifluralin for many single microbial strains (from bacteria, actinomycetes and micromycetes) grown in liquid and/or on solid media, (b) to stimulate active growth of some microorganisms in media with high concentrations of trifluralin (in some cases the growth rate was comparable to and even surpassing the one in the standard cultivation media), (c) to increase the ability of different consortia of bacteria and micromycetes to grow in the media with trifluralin as the only source of carbon, nitrogen and energy, (d) to increase the survival and activity of soil microbial biomass in virgin soils artificially contaminated with trifluralin, (e) to stimulatethe survival and activity of exogenous microorganisms introduced into the polluted soil for the purpose of remediation, (f) to stimulate the activity of soil microbial biomass in the polluted soil including after introduction of exogenous microorganisms for the purpose of remediation, $(\mathrm{g})$ to cause no observable toxic effects upon the soil microbial biomass when applied in concentrations below $400 \mathrm{mg} / \mathrm{kg}$. 